(a) (1) https://creativecommons.org/licenses/by/4.0/

ARTIGO

\title{
AVALIAÇÃO DEMOCRÁTICA DAS APRENDIZAGENS HISTÓRICAS: DESAFIOS À DIDÁTICA DA HISTÓRIA
}

\author{
MARCUS LEONARDO BOMFIM MARTINS ${ }^{1}$ \\ ORCID: https://orcid.org/0000-0003-3369-9260
}

\begin{abstract}
RESUMO: O objetivo deste artigo é propor uma reflexão teórica sobre as possibilidades de construção de mecanismos de avaliação da aprendizagem no âmbito da história escolar em uma perspectiva democrática. Os aspectos democratizantes considerados ao longo da argumentação referem-se a possibilidades de refigurações de narrativas históricas que, simultaneamente, garantam espaços de subjetivação, identificação e objetivação na relação com o conhecimento histórico escolar, e preservem o valor de verdade da narrativa refigurada em meio aos processos avaliativos. A partir de uma abordagem discursiva inscrita na pauta pós-fundacional, o texto investe na desestabilização de sentidos de aprendizagem, avaliação e Didática da História para propor uma avaliação democrática das aprendizagens históricas.
\end{abstract}

Palavras-chave: Ensino de História, aprendizagem histórica, didática da História, conhecimento histórico escolar, avaliação da aprendizagem.

\section{DEMOCRATIC EVALUATION OF HISTORICAL LEARNING: CHALLENGES TO THE DIDACTICS OF HISTORY}

\begin{abstract}
This article aims to propose a theoretical consideration on the possibilities of building mechanisms to evaluate History learning in school environments in a democratic perspective. The democratizing aspects considered throughout the argument refer to possibilities of refiguration of historical narratives that simultaneously guarantee spaces of subjectivation, identification and objectification in relation to schoolar historical knowledge, and preserve the truth value of the refigured narrative amidst evaluation processes. From a discursive approach inscribed in the post-foundational agenda, the text invests in the destabilization of meanings of learning, evaluation and Didactics of History to propose a democratic evaluation of historical learning.
\end{abstract}

Keywords: History teaching, historical learning, didactics of History, scholar history knowledge, learning evaluation.

\section{EVALUACIÓN DEMOCRÁTICA DE LOS APRENDIZAJES HISTÓRICOS: RETOS A LA DIDÁCTICA DE LA HISTORIA}

\footnotetext{
${ }^{1}$ Universidade Federal de Juiz de Fora (UFJF). Juiz de Fora, MG, Brasil. <marcus.bomfim@gmail.com> Educação em Revista|Belo Horizonte|v.36|e227098|2020
} 
RESÚMEN: El objetivo de este artículo es proponer una reflexión teórica sobre las posibilidades de construcción de mecanismos de evaluación del aprendizaje en el ámbito de la Historia escolar en una perspectiva democrática. Los aspectos democratizadores considerados a lo largo de la argumentación se refieren a posibilidades de refiguración de narrativas históricas que, simultáneamente, garanticen espacios de subjetivación, identificación y objetivación en la relación con el conocimiento histórico escolar, y preserven el valor de verdad de la narrativa refigurada em medio a procesos evaluativos. A partir de un abordaje discursivo inscrito en la pauta posfundacional, el texto apuesta a la desestabilización de sentidos de aprendizaje, evaluación y Didáctica de la Historia para proponer una evaluación democrática de los aprendizajes históricos.

Palabras clave: Enseñanza de Historia, aprendizaje histórico, didáctica de la Historia, conocimiento histórico escolar, evaluación del aprendizaje. 


\section{INTRODUÇÃO}

O presente texto origina-se a partir de uma pesquisa desenvolvida no âmbito de um doutoramento na área de Ensino de História. Tal pesquisa se inscreve nas fronteiras borradas entre os campos do Currículo e do Ensino de História, e em diálogo com os campos da História, da Didática e da Avaliação. Defendo a vinculação intrínseca entre ensino e aprendizagem e as práticas a eles associadas nas relações escolares, com destaque para a avaliação, e as singularidades epistemológicas do "ensino de". A pesquisa teve como foco enfrentar teoricamente as inquietudes relacionadas a legitimação de saberes e de formas de com eles se relacionarem, docentes e discentes, em meio aos processos avaliativos da disciplina História. São, pois, parte das apostas políticas e teóricas ali produzidas que ora apresento a pretexto de contribuir para as discussões sobre aprendizagens históricas e seus necessários processos de validação.

Esse artigo inscreve-se em uma abordagem discursiva na perspectiva teórica pósfundacional. Nessa perspectiva o prefixo "pós" não significa uma negação do fundamento, mas implica em "abrirmos mão de certezas e verdades apoiadas em fundamentos metafísicos que se situam fora do jogo da linguagem" (GABRIEL, 2013, p. 4). Para o pós-fundacionismo a realidade social não aparece como algo a ser desvendado, mas compreendido a partir da sua infinidade de formas, das várias possibilidades de se alcançar múltiplas verdades, contingentes e precárias. Nesse sentido, me aproximo de teorizações antiessencialistas por entender que "não existe um sentido previamente fixado, passível de identificar as coisas e sujeitos desse mundo pelas suas "positividades plenas." (GABRIEL, 2013, p. $5)$ ".

Dentre as abordagens discursivas disponíveis opto aqui pela Teoria do Discurso de Ernesto Laclau e Chantal Mouffe (2015). Trata-se de uma teoria de análise do social na qual a dimensão ontológica do político ocupa um lugar de destaque. Partindo do pressuposto que a realidade social não está dada a priori, mas que é construída politicamente, e que o acesso à materialidade se dá pelo discurso, defendo a potência desta teoria para analisar como discursos adquirem estabilidade no mundo social, o que Laclau chama de hegemonia, mas também como eles podem ser desestabilizados.

No caso desse texto, tal entendimento me permite compreender que o que tem sido fixado como aprendizagem histórica válida no tempo presente - em meio a processos avaliativos - é definido politicamente, em jogos de poder no qual as relações assimétricas entre sujeitos diversos definem, provisoriamente, uma hegemonia, de forma que sentidos outros podem ser investidos, desestabilizando o que está precariamente fixado.

O movimento desse texto é de investimento em reflexões sobre um valor de verdade específico para o conhecimento histórico produzido no e para o ensino nas escolas da educação básica articulado a instrumentos avaliativos que possibilitem ao aluno/a produzir uma narrativa que seja considerada autoral e verdadeira, isto é, uma narrativa que não se limite a ser uma cópia idêntica da configuração produzida pelo professor no contexto da sala de aula.

Nesse sentido, organizo esse texto da seguinte forma. Na primeira seção problematizo o significante aprendizagem de forma a incorporar aos seus sentidos a categoria relação com o saber. Depois apresento uma proposta de articulação entre as especificidades do conhecimento histórico escolar e da Didática da História, deixando para a última parte uma proposta de avaliação específica para as aprendizagens históricas.

\section{COLOCANDO O SIGNIFICANTE APRENDIZAGEM"SOB RASURA"}

Tradicionalmente a aprendizagem tem sido pensada, no âmbito escolar, como sinônimo de aquisição relacionada à noção de quantidade, ou melhor, de quantificação, de coisas que possam ser medidas. Essa tradição reverbera em uma relação com um saber-objeto, cuja existência independe do sujeito. A objetivação é a consciência por parte do sujeito dessa apropriação (CORRÊA; PASSOS; ARRUDA, 2018). Em outros termos, trata-se de pensar a aprendizagem como consciência do sujeito daquilo que ele adquiriu durante o processo de ensino-aprendizagem. Essa ideia decorre também de outra tradição que se relaciona ao fato de se aceitar que todo o nosso aprendizado provém da experiência 
consciente (JARVIS, 2015), leitura esta que reatualiza a crença no sujeito autônomo e centrado forjado na e pela Modernidade. Sujeito e objeto (no caso desse último trata-se aqui do saber/conhecimento) possuem, nessa perspectiva, absoluta exterioridade um em relação ao outro.

No campo da Didática no Brasil, caracterizado por relevante pluralidade teórica, têm prevalecido as perspectivas cognitivistas, construtivistas e construcionistas como hegemônicas para conceber as aprendizagens. José Carlos Libâneo, um dos representantes mais proeminentes dessa perspectiva, aposta nos meios de aquisição de conceitos científicos e desenvolvimento de capacidades cognitivas como elementos indissociáveis da aprendizagem escolar (LIBÂNEO, 2004). Para ele o compromisso da didática, tomada como saber pedagógico e não como campo, é a busca da qualidade cognitiva das aprendizagens, isto é, aprender a pensar. Nesse sentido, o autor crê na atividade de aprendizagem como o núcleo da escola. Aprender, nessa lógica, está relacionado ao desenvolvimento de competências e habilidades cognitivas, sendo o papel do professor promover as mediações cognitivas entre aluno e conhecimento, mais uma vez vistos como exteriores um ao outro.

Esse paradigma cognitivista, dominante nas explicações sobre ensino e aprendizagem escolar (CHAIB, 2015), se concentra em explicar a aprendizagem, tomada como aquisição, como um produto dos atributos psicológicos das pessoas, tais como inteligência, maturidade, desenvolvimento genético, motivação e atitude. Essa estruturação discursiva tende a desconsiderar dimensões psicanalíticas, históricas, sociológicas e pedagógicas no processo de obtenção (para realçar o valor semântico de posse) de aprendizagens, deslocando para os sujeitos a exclusiva responsabilidade pelo sucesso ou fracasso das relações de ensino-aprendizagem.

Não se trata aqui, pois, de negar a importância de elementos cognitivos nos processos de aprendizagem, mas mitigar seu status de fundamento último no processo de definição de aprendizagem. Ademais, mobilizar termos como "tomada de consciência" e "estratégias" pode remeter a uma essencialização dos sujeitos que só seriam capazes de aprender (no sentido de adquirir conhecimento) em um processo absolutamente consciente e controlado.

As formas tradicionais de conceber a aprendizagem pressupõem, pois, que ela tem relação com aquisições de algo "externo", algo que existia antes do ato de aprender e que, o seu resultado, tornase algo cuja posse passa a ser do aprendente. Esse parece ser o foco principal da escola e a via de acesso dos jovens escolarizados ao que Biesta (2017) com base em Lingis (1994) nomeia de "comunidade racional", e que apresenta como característica principal a instituição de uma ordem comum, uma linguagem comum, um discurso comum, de forma que os sujeitos são despersonalizados, importando, portanto, o que é dito, e não quem diz. Assim, "na comunidade racional somos, portanto, intercambiáveis" (BIESTA, 2017, p. 82, grifo do autor). Ainda de acordo com este autor:

As escolas propiciam aos estudantes uma voz muito específica, a saber, a voz das comunidades racionais representada por meio do currículo. Ao dar aos estudantes essa voz, as escolas não só legitimam certos modos de falar. Ao mesmo tempo, elas deslegitimam outros modos de falar. (Isso, como os sociólogos da educação nos mostraram, explica por que alguns estudantes têm de desaprender muito mais do que outros para ter sucesso no sistema educacional). (BIESTA, 2017, p. 83).

Um gabarito de um instrumento avaliativo qualquer produzido por quem elaborou tal instrumento de forma a permitir que qualquer pessoa, de posse deste gabarito, possa corrigir a avaliação, desconsiderando, portanto, os possíveis contornos específicos da relação vivida entre professor e aluno no processo de ensino-aprendizagem, e frases do tipo "eu sei que você sabe, mas não foi o que você escreveu" comumente proferidas por professores, são exemplos da intercambialidade que caracteriza os processos escolares.

A escola e suas práticas educacionais, e destacadamente a avaliação, cumprem esse papel na constituição e reprodução da comunidade racional, legitimando e deslegitimando modos de falar. Faz sentido, portanto, a crítica produzida por Bondía (2002, p. 23): "estou cada vez mais convencido de que os aparatos educacionais também funcionam cada vez mais no sentido de tornar impossível que alguma coisa nos aconteça.". 
Essa crítica indica uma preocupação com uma perspectiva de aprendizagem que extrapole a expectativa de que os alunos sejam capazes de internalizarem e reproduzirem o discurso comum que os qualificam a se tornarem membros da comunidade racional produzida e representada pela escola. A proposta do autor é que as escolas sejam lugares de experiência, entendido como "aquilo que nos acontece, o que nos toca" (BONDÍA, 2002, p. 21).

É preciso sublinhar, porém, que a crítica aqui trazida não consiste em negar qualquer tipo de validade de pensar a escola como espaço de consumo de conteúdos, valores, habilidades e competências, ou, em outros termos, expressões da arte, da tecnologia e da ciência acumulados historicamente no seio de uma cultura e objetivados como conhecimento escolar, pois uma das funções da educação sobre a qual parece haver poucas divergências é o seu papel de apresentar (um) mundo aos sujeitos, mundo este que já é habitado por outros e que possui alguns códigos que precisam ser partilhados para garantir a dimensão pública do mesmo.

Dessa forma, a comunidade racional não é per si o que impede uma educação, ou de forma mais abrangente, uma ordem social mais democrática e menos excludente. Ademais, tirar da escola o papel do ensino de conteúdos, habilidades e competências pode ser extremamente perverso com quem mais precisa da escola, principalmente em uma sociedade como a brasileira na qual as enormes desigualdades educacionais e sociais se retroalimentam.

Biesta (2017) nomeia como linguagem da aprendizagem algumas tendências que enfatizam as aprendizagens e colocam como função da escola satisfazer as necessidades do aprendente, definidas previamente, cabendo a essa instituição entregar sua mercadoria. Nessa perspectiva, questões sobre o conteúdo e o objetivo da educação são formuladas em termos do que "o cliente" (aluno) ou "o mercado" deseja, secundarizando ou mesmo impossibilitando uma discussão aberta e democrática sobre o conteúdo e o objetivo da educação, afinal os grupos de interesse que apoiam e investem nessas concepções entendem este estado das coisas como algo plenamente estabelecido, atuando apenas no sentido de prover condições de adaptação a esta ordem.

A linguagem da aprendizagem impede que os indivíduos se "tornem presença", ou seja, que habitem o mundo "como seres singulares e únicos", o que só é possível "por meio de nossas relações com os outros que não são como nós" (BIESTA, 2017, p. 56). Na mesma linha, Bondía (2002) argumenta sobre o saber da experiência - o sentido (ou sem sentido) do que nos acontece (experiência), de forma que se trata de um saber particular, subjetivo, relativo, contingente e pessoal, não podendo ser apartado do indivíduo, constituindo-se em uma forma singular de estar no mundo, sendo uma atuação ética (um modo de conduzir-se) e estética (um estilo). Biesta (2017, p. 48), no entanto, salienta que "vir ao mundo não consiste definitivamente em autoexpressão". Essa ressalva é pertinente para sublinhar o caráter relacional e ético de vir ao mundo, de se tornar o sujeito da experiência.

A proposta do autor da passagem de uma linguagem da aprendizagem, atualmente identificada como hegemônica, para uma linguagem da educação que não a perceba como processo de "produção" de um tipo particular de subjetividade (apenas aquela necessária para a reprodução da comunidade racional), especialmente o sujeito racional autônomo da educação moderna, está assentada em três conceitos.

O primeiro conceito é o de Confiança. Educar é correr riscos (não aprender o que queria, aprender o que não imaginaria que poderia aprender, aprender algo que talvez preferisse não aprender, sofrer com o impacto da aprendizagem) e correr riscos exige confiança, que é incalculável. Embora reconheça que nem toda aprendizagem acarrete um volume similar de risco, o autor argumenta que toda aprendizagem possa conduzir a mudanças inesperadas. Para o autor,

Sugerir que a educação pode ser e deve ser livre de risco, que os aprendentes não correm nenhum risco ao se engajarem na educação, ou que os resultados da aprendizagem podem ser conhecidos ou especificados de antemão é uma representação errônea daquilo em que consiste a educação (BIESTA, 2017, p. 45).

O segundo conceito é o de Violência. A proposta do autor é substituir esta ideia de aprendizagem calcada em metáforas possessivas, ligadas à ideia de aquisição, por uma noção de resposta a uma desintegração. A aprendizagem como resposta participa da produção de subjetividades (que são 
inteiramente sociais), permitindo ao sujeito aprendente "tornar-se presença". A violência educacional consiste, pois, na interferência sobre a soberania do sujeito propondo questões difíceis e criando encontros difíceis. Para ele:

As duas maneiras de considerar a aprendizagem - como aquisição e como resposta - poderiam ser igualmente válidas, isto é, dependendo da situação em que propomos questões sobre a definição da aprendizagem (...) mas a segunda concepção de aprendizagem é a educacionalmente mais significativa, se admitimos que a educação não é apenas a transmissão de conhecimento, habilidades e valores, mas diz respeito à individualidade, à subjetividade ou à personalidade dos estudantes, com sua "vinda ao mundo" como seres únicos e singulares (BIESTA, 2017, p. 47, grifos do autor).

Por fim, mas não menos importante, o conceito de Responsabilidade. Trata-se de uma responsabilidade ilimitada e incalculável, pois se assume responsabilidade pela singularidade do estudante, isto é, por alguém que não conhecemos e não podemos conhecer. Como diz o próprio Biesta (2017):

Se a educação consiste em criar oportunidades para que os estudantes venham ao mundo, e se consiste em propor as questões difíceis que tornam isso possível, fica claro que a primeira responsabilidade do educador é pela subjetividade do estudante, pelo que permite ao estudante ser um ser singular e único (p. 50).

Esses três conceitos ou dimensões que para Biesta (2017) instituem uma relação educacional buscam romper com a onipresença da linguagem da aprendizagem nos mais variados discursos educacionais contemporâneos. Nesse sentido, recorro a Gabriel (2018), que mobiliza a categoria relação com o saber, apostando em seu potencial de mediação entre a tradicional concepção de aprendizagem como aquisição de um conhecimento externo ao sujeito e a tradução de aprendizagem como resposta ao que nos acontece, defendendo ainda que esta pode qualificar aquela, operando, pois com a indissociabilidade dos processos de subjetivação (tornar-se presença e sujeito da experiência) e objetivação (do conhecimento e do sujeito educado/escolarizado, o sujeito que aprende). Na perspectiva de aprendizagem como resposta,

podemos dizer que alguém aprendeu alguma coisa não quando for capaz de copiar e produzir o que já existia, mas quando alguém responde ao que não é familiar, ao que é diferente, ao que desafia, irrita ou até perturba. Então a aprendizagem se torna uma criação ou uma invenção, um processo de introduzir algo novo no mundo: a resposta única de alguém. (BIESTA, 2017, p. 97).

Gabriel (2018, p. 233) define relação com o saber como "relação de acesso ao mundo por meio de processos ou sistemas de significação produzidos em um espaço-tempo específico". O contexto deve ser levado em consideração para pensar a dimensão social dessa categoria que não estabelece uma ligação entre duas essências (sujeito e saber), de forma que "é a própria relação que precisa ser considerada logo de saída" (CHARLOT, 1997 apud GABRIEL, 2018, p. 239). Dito de outra forma, o potencial heurístico dessa categoria está em pensar a relação como lugar de emergência do sujeito e do saber, pois como afirma a autora, "um saber tem sentido e valor somente em referência às relações que o sujeito produz com o mundo, consigo e com os outros" (GABRIEL, 2018, p. 242).

Apostar então na categoria relação com o saber é potencialmente fértil, portanto, para que nos "tornemos presença pela maneira como nos envolvemos com aquilo que aprendemos" (BIESTA, 2017, p. 127), de forma que o conhecimento objetivado seja contingencialmente estruturado para atender às demandas de desejo pelo mundo, pelos outros e por si mesmo que são mobilizadas em meio aos processos de subjetivação.

Essa relação com o saber também é interpelada pela configuração epistemológica desse saber que será colocado em relação nos processos educacionais. Nesse sentido, na seção a seguir exploro possibilidades de estruturação epistemológica do conhecimento escolar, e mais especificamente, do conhecimento histórico escolar, em meio a relações com a Didática da História. 


\title{
CONHECIMENTO HISTÓRICO ESCOLAR E DIDÁTICA DA HISTÓRIA: RELAÇÕES INCONTORNÁVEIS
}

O adjetivo escolar que acompanha o substantivo conbecimento bistórico tem como função distingui-lo daquele cujo foco não seja especificamente o uso em situação de escolarização. Isso, no entanto, já pressupõe a existência de um conhecimento histórico voltado para a educação e outro que não tem essa preocupação, ao menos como prioridade. Assim, se há um escolar que qualifica certo conhecimento histórico, interessa aqui apresentar os elementos que o configuram, bem como o que serve como interrupção de seu processo constituinte, servindo-lhe, pois, de exterior constitutivo.

Defender a primazia ou exclusividade da ciência histórica como lugar de produção do objeto a ser ensinado nas escolas negligencia as singularidades da cultura escolar (e da cultura da escola) que interpelam as relações entre os sujeitos que circulam por esse espaço e as relações desses sujeitos com os conhecimentos legitimados como objeto de ensino. A aposta que aqui faço é a da potência da incorporação das questões da cultura escolar no processo de produção do conhecimento escolar, sem que isso represente quebrar vínculos entre o conhecimento histórico acadêmico e o conhecimento histórico escolar e, ao mesmo tempo, não conceba este como um amalgama mal feito a partir daquele, pois "a incorporação de contribuições teóricas do campo da ciência de referência não produz uma réplica, mas sim um conhecimento com características originais, próprias da cultura escolar." (GABRIEL; MONTEIRO, 2014, p. 34).

Trata-se, de acordo com Plá (2013a), de um conhecimento produzido em outro lugar e que possui uso distinto, que constrói seus próprios regimes de historicidade e que possui suas próprias formas de verificabilidade. É uma forma particular, histórica e cultural de significar o passado. Para ele:

Ainda que vinculado de várias maneiras com o conhecimento científico, tem outra procedência que não é a fonte histórica ou o rigor acadêmico, e sim o uso público do passado dentro de uma sociedade. O resultado desse processo é o que denomino de conhecimento histórico escolar. (PLÁ, 2013a, p. 475, tradução minha).

Em outros termos, trata-se de incluir na cadeia equivalencial desse conhecimento escolar, elementos outros que não aqueles exclusivamente da ciência de referência, como destaca Gabriel (2017):

\begin{abstract}
Trata-se assim de apostar na possibilidade de pensar a história-ensinada não mais como uma versão necessariamente simplificada e reduzida do conhecimento histórico produzido pelas pesquisas acadêmicas, mas sim como uma configuração de ordem epistemológica e axiológica (ética-político-cultural) com grau de especificidade e autonomia suficientes para que ela possa ser percebida e legitimada como um saber diferenciado e estratégico nas disputas pelas interpretações de sentidos do mundo. (GABRIEL, 2017, p. 25, grifos meus).
\end{abstract}

Os grifos assinalados no excerto acima apontam para a definição de limites no processo de configuração desse conhecimento, pois se esse saber não é o mesmo, tampouco uma versão reduzida do historiográfico, é preciso que haja mecanismos de preservação da sua condição de verdadeiro, para que ele seja legitimado para ser ensinado nas escolas.

Gabriel e Moraes (2014) defendem que o conteúdo configura-se como uma unidade diferencial dentre outras que se articulam para configurar o conhecimento escolar. Essa aposta não reduz conhecimento escolar a conteúdos, pois reconhece a presença de outros elementos diferenciais nas práticas articulatórias definidoras deste conhecimento que tem na escola o seu espaço privilegiado de estabelecimento de relações, como, por exemplo, competências, valores, atitudes, saberes do senso comum, dos meios de comunicação de massa, etc.

E é este conhecimento "produzido e legitimado em função dos respectivos regimes de verdade das diferentes áreas disciplinares” (GABRIEL; MORAES, 2014, p. 32) que aqui está sendo definido/nomeado como conteúdo. Assim, incluir, pois, a unidade diferencial conteúdo na cadeia equivalencial definidora de conhecimento escolar, implica reconhecimento dos "fluxos de cientificidade" (GABRIEL; MORAES, 2014) na produção daquilo que é considerado válido a ser ensinado nas escolas da educação básica. É, nesse sentido, que se argumenta aqui que é este elemento que coloca o conhecimento 
escolar no domínio do verdadeiro, corroborando a defesa que Laville (1999) faz de que é impossível ensinar História sem conteúdos.

Considero, contudo, necessário esclarecer que na perspectiva teórica aqui assumida, também a ciência é produzida discursivamente, ou seja, em torno dela se disputam sentidos de verdade. Outrossim, "assumir a centralidade do papel dos fluxos de cientificidade na definição de conhecimento escolar não significa operar com a ideia de 'a' verdade em uma perspectiva a-histórica, mas sim assumir o compromisso da escola com o 'valor de verdade "'. (GABRIEL; MORAES, 2014, p. 32).

É, pois, no campo da epistemologia que as configurações do conhecimento histórico escolar são forjadas em meio às disputas que sinalizam a ausência de incompatibilidade entre questões de ordem política e epistemológica, principalmente quando o que está em jogo é um conhecimento que se diferencia dos demais pela centralidade de questões temporais para pensar a humanidade, o que implica, necessariamente, o apelo às questões axiológicas.

Reflexões nesse campo reconhecem a diversidade de formas de conhecimento e seus processos de validação (MONTEIRO, 2007), pois a validade de apostar na epistemologia está na possibilidade de afirmar a existência de conhecimentos verdadeiros, válidos para serem ensinados em uma determinada área disciplinar (GABRIEL, 2017). Ou seja, defender a participação decisiva da cultura escolar no processo de produção dos saberes escolares não significa um "tudo pode", pois, o conhecimento escolar, na abordagem aqui privilegiada, é visto como "conhecimento com rigor teórico e metodológico, que representa uma perspectiva e que precisa ser validado pelos pares, sujeito necessariamente a críticas e superações.” (MONTEIRO; PENNA, 2011, p. 192). Assim, a epistemologia que confere o valor de verdade ao conhecimento histórico escolar não deve ser apenas aquela situada na ciência histórica, mas como defende Penna (2014), uma epistemologia que incorpore em suas reflexões questões relativas à função social dos saberes por meio do ensino.

Incorporando questões de poder ao campo da epistemologia, Gabriel (2017) cunha o conceito de Epistemologia Social Escolar para dar conta das dimensões política e histórica como constituintes da noção de saber válido e legítimo para ser ensinado e aprendido nas escolas e, consequentemente, avaliado, que é o que aqui me interessa. Nesse sentido, é que situo meu entendimento sobre o ser e o fazer da Didática da História.

O entendimento de conhecimento histórico escolar aqui mobilizado insere-se em uma perspectiva de Didática da História entendida como "lugar de fronteira" - lugar este "onde são demarcadas diferenças, mas onde também é possível produzir aproximações, diálogos, ou distanciamento entre culturas que entram em contato." (MONTEIRO; PENNA, 2011, p. 194), no caso, as culturas histórica e escolar, afastando-se, portanto, da ideia de pensa-la como subdisciplina da ciência histórica (SADDI, 2010). É nesse lugar que se estabelece o corte antagônico do que é e do que não é válido como conhecimento histórico escolar legítimo e verdadeiro.

Gabriel (2015) entende que a interlocução entre os campos da Educação e da História "encontra-se profundamente comprometida enquanto estiver pautada em um terreno epistemológico minado por relações assimétricas de poder historicamente estabelecidas entre essas duas tradições disciplinares" (GABRIEL, 2015, p. 89). A assimetria à qual ela se refere é a que coloca a ciência histórica acima das ciências da educação para pensar o objeto da Didática da História, como proposto por autores como Saddi (2010), dentre tantos outros.

Sublinhando outro aspecto do significante "fronteira", o de interseção, Gabriel (2015) propõe o termo cultura histórica escolar para dar conta da articulação entre cultura histórica e cultura escolar. Da cultura histórica ela destaca a questão das temporalidades, apostando nos conceitos ricouerianos de narrativa bistórica e identidade narrativa para fazer avançar essa discussão. No que diz respeito à cultura escolar, a autora destaca a relação com o conhecimento nesse espaço-tempo específico.

Cerri (2010) defende uma Didática da História que articule teoricamente os conceitos de consciência histórica de Rüsen - entendida como um grau de consciência da relação entre passado, presente e futuro que orientam intencionalmente suas práticas; de ação comunicativa de Habermas - vista como interação com o objetivo de alcançar uma compreensão sobre a situação em que ocorre a interação e sobre os respectivos planos de ação com vistas a coordenar suas ações pela via do entendimento; e epistemologia dialógica de Paulo Freire - conscientização como elemento dialógico e bilateral que encarna 
uma postura teórica e política. Entendo que essa argumentação extrapola os limites de uma dependência absoluta da ciência histórica, pois não necessariamente a narrativa histórica sem fins escolares, produzida pelos historiadores, compreendem os conceitos de ação comunicativa e epistemologia dialógica.

É, pois, no campo da Didática da História, percebido como arena discursiva na qual se disputam sentidos sobre o ensino escolar da História, onde reverberam definições e validações sobre conteúdos, função docente, aprendizagem, metodologias e conhecimento histórico escolar, de forma a preservar a escola como espaço no qual se oferta e com o qual se relaciona com um conhecimento verdadeiro e que não pode ser acessado em outros espaços de consumo do passado. Trata-se de um espaço atravessado por tensões e assimetrias que configuram seu caráter disputado e contingente.

Os instrumentos avaliativos no âmbito dessa disciplina escolar constituem-se, portanto, como terreno privilegiado desse processo na medida em que são eles que em última instância vão definir as configurações legítimas desse conhecimento em termos de conteúdos, habilidades, competências, em suma, em relações com o saber. Em outras palavras, é por meio das avaliações que narrativas históricas e formas de se relacionar com elas serão validadas ou deslegitimadas.

Lautier (2011) sinaliza uma discrepância entre o nível de conhecimento exigido para avaliações normativas e o que se pretende em termos de formação cidadã, como se houvesse um hiato que impedisse uma avaliação das aprendizagens históricas que contemplasse o domínio de conteúdos e a formação cidadã. Velasco (2013) também chega a essa conclusão tendo como contexto de pesquisa o Rio de Janeiro neste século XXI, de forma que as avaliações no âmbito da história escolar tendem a não avaliar o que escapa das finalidades científicas, escamoteando a função de formação cidadã, e reatualizando a tão combatida e criticada, mas sempre presente, memorização de conteúdos.

Uma possível saída teórica para esse fosso, e que explorarei de forma mais profícua na seção seguinte, vem de um elemento que institui o pensamento histórico, no qual convergem suas versões acadêmica e escolar: a estrutura narrativa. Gabriel e Monteiro (2014) fazem a defesa da narrativa como elemento constitutivo do saber histórico em função do seu papel articulador no tempo histórico, pois ela absorve a tensão entre construção de sentido e a busca da verdade, entre compreensão e explicação. Em outros termos, Gabriel (2017) entende que a estrutura narrativa é responsável pela inteligibilidade do conhecimento histórico. Pensando mais especificamente no ensino, Cerri (2010) entende que articular passado, presente e futuro - elementos articulados em uma narrativa - não é apenas um recurso para prender a atenção do aluno, mas estrutura de pensamento histórico.

Assim, na seção seguinte proponho-me a pensar em possibilidades de uma avaliação no contexto do ensino de História que contemple possibilidades outras de refigurações narrativas por meio da articulação do "tornar-se presença" com os conhecimentos históricos escolares.

\section{AVALIAÇÃO DEMOCRÁTICA E APRENDIZAGEM HISTÓRICA: POSSIBILIDADES NARRATIVAS}

Como já abordado, as possibilidades de experiência e de se tornar presença por parte dos estudantes configuram-se como alguns dos elementos democratizantes dos processos educacionais. Falar da implicação do aluno no processo de avaliação se refere, pois, a criar condições para que ele possa vir ao mundo de forma singular e legitimada, sem que isso signifique apenas repetir a palavra dita por outrem. Nesse sentido, retomo Biesta (2017) para pensar os instrumentos avaliativos e/ou seus usos a partir da noção de funcionalismo negativo. Isso significa, mais do que gerar possibilidades vistas como satisfatórias ou suficientes para que os sujeitos se tornem presença e produzam experiência - o que tende a reforçar um apelo por uma dimensão técnica que se sobreporia a dimensão política da avaliação - pensar em algo que "não pretende prescrever como uma construção deve ser usada e como os usuários devem se comportar, visando, em vez disso, não tornar algumas ações e eventos impossíveis." (BIESTA, 2017, pp. 146-147, grifos do autor). Esse posicionamento permite, simultaneamente, evidenciar a "impossibilidade de os arquitetos escaparem completamente do funcionalismo" (BIESTA, 2017, p. 151), mas também as brechas ou fissuras possíveis para outros usos, diferentes dos que foram previstos. 
A analogia do arquiteto com o professor no contexto de elaboração de seus instrumentos avaliativos é produtiva na medida em que o humaniza, colocando-o no domínio do político e, ao mesmo tempo, tomando seu ofício como espaço-tempo de ação (no sentido de Hannah Arendt (2007) que visa garantir, ou não impedir, outras ações, reconhecendo, porém, que lhe escapa o domínio completo do fechamento de sentido das ações daqueles que estão posicionados nos sistemas educacionais como sujeitos aprendentes.

Essa dupla responsabilidade docente contribui para que se pense a avaliação em diálogo com a ideia de espaço-disjuntivo de Biesta (2017), pois este é o espaço da transgressão mútua entre espaço e evento, isto é, uma ordem ameaçada pelo próprio uso que permite, e vice-versa. É ao mesmo tempo espaço e evento. Pensar a avaliação nessa lógica significa admitir que formas singulares de vir ao mundo no momento avaliativo podem colocar em risco os próprios objetivos definidos aprioristicamente em relação ao uso do espaço avaliativo, o que não é em si algo que se deva combater, sendo inescapável e impossível de ser previsto. Ademais, esse risco faz parte da responsabilidade inerente aos processos educacionais em perspectiva democrática.

O funcionalismo do qual não tem como escapar o professor e a aposta no conhecimento escolar como bem simbólico incontornável no processo de democratização escolar fazem com que o conhecimento se torne o principal referente para a avaliação. Assim, a avaliação informa sobre os sentidos de conhecimento fixados e valorizados nos contextos nos quais as relações de ensino-aprendizagemavaliação se desenvolvem. Nesse sentido, Álvarez Méndez (2001), contribui ao destacar que:

A avaliação está estreitamente ligada à natureza do conhecimento. Uma vez esclarecida esta, a avaliação deve ajustar-se a ela se pretende ser fiel a manter a coerência epistemológica que lhe dá consistência e credibilidade práticas, mantendo a coesão entre a concepção e as realizações concretas. (ÁLVAREZ MÉNDEZ, 2001, p. 27, tradução minha).

Ainda que se desloque para o político a questão da natureza do conhecimento, em consonância com a abordagem pós-fundacional que orienta a tessitura desse texto, é coerente a articulação entre sentidos de conhecimento e práticas avaliativas, pois a estruturação epistemológica do conhecimento ajuda a balizar as possibilidades de validação de relações que com ele possam ser estabelecidas. No caso da disciplina História, por exemplo, pensar a estrutura do conhecimento nela veiculado apenas como adaptação de linguagem do conhecimento produzido academicamente é diferente de reconhecê-la com epistemologia própria e que dialoga com outras áreas do conhecimento, notadamente os conhecimentos pedagógicos, e os saberes dos sujeitos envolvidos nas relações de ensinoaprendizagem-avaliação, de forma que nesse espaço-tempo as possibilidades de validar, ou não, determinadas relações estarão diretamente relacionadas às concepções envolvidas.

Investir na diversificação de instrumentos de forma a garantir - ou não impedir - algumas ações, apresenta-se também como antídoto ao predomínio das avaliações nas quais se valoriza apenas o que pode ser medido, que informam apenas sobre uma relação aquisicionista com o conhecimento. A avaliação da aprendizagem como espaço-disjuntivo articulada ao funcionalismo negativo abre um leque de possibilidades para que se extrapole a perspectiva factual e os níveis elementares de cognição na relação com o conhecimento.

Há importantes desafios no processo de construção de uma avaliação específica para a história escolar, mas, ao mesmo tempo, aposto na possibilidade de enfrentamento desse desafio por meio da problematização do conhecimento histórico escolar. Nesse sentido, explorando seu processo de construção por meio do aprofundamento de aspectos anteriormente levantados, aposto que tal processo oferece subsídios para pensar na viabilidade de instrumentos avaliativos inscritos em sua própria epistemologia, que se situa no âmbito da Didática da História na perspectiva defendida na seção anterior.

Sendo, pois, como afirma Paul Ricoeur, uma categoria da ação, a narrativa, e mais especificamente a identidade narrativa, oferece um arcabouço teórico-metodológico capaz de tornar possível a avaliação das aprendizagens históricas, com todo o sentido de validação que toda prática avaliativa carrega, para além da incomunicabilidade da experiência psíquica do autor, de forma que o malentendido entre o sentido objetivo e a intenção subjetiva do autor é inevitável (RICOEUR, 2011). Em 
outros termos, para o inescapável hiato entre a subjetividade do autor, seja na condição de avaliado, seja na condição de avaliador, e o que é por ele objetivado em meio a processos avaliativos, a identidade narrativa emerge como opção.

É justamente a preocupação em construir e expor o mundo em perspectiva temporal que leva Ricoeur a desenvolver sua obra. Segundo esse filósofo, esse mundo precisa se tornar inteligível e é a narrativa que permite que ele assim o seja ao delinear os traços da experiência temporal, pois toda narrativa possui uma necessidade interna de coerência, independente de um mundo fora do texto. A inteligibilidade narrativa se dá num triplo movimento interpretativo - o círculo hermenêutico - não linear, contingente e sempre incompleto: prefiguração (competência de acompanhar uma história); configuração (construção da intriga, do texto); refiguração (encontro do mundo do texto com o mundo do leitor), de forma que é na narrativa que o sentido se constitui como ação.

O próprio Ricoeur, porém, faz uma importante ressalva: “a leitura está no texto, mas a escrita do texto antecipa as leituras futuras. Com isso, o texto que deveria prescrever a leitura é atingido pela mesma indeterminação e pela mesma incerteza que as leituras futuras." (RICOEUR, 1997, p. 285, grifos do autor). Pensando na avaliação das aprendizagens históricas, essa indeterminação das leituras da qual fala o filósofo é passível de ser articulada à noção de espaço-disjuntivo (BIESTA, 2017). Com efeito, se um instrumento avaliativo pode ser o lugar da ordem ameaçada pelo uso que permite, no âmbito do ensino de História o risco de transgressão torna-se ainda mais acentuado pelo caráter narrativo de seu conhecimento que conduz a uma viabilidade de refiguração temporal de experiências. Em outros termos, reconhecer a pluralidade de possibilidades de refigurações narrativas amplia o leque de aprendizagens históricas válidas, à medida que esse compromisso está na elaboração do texto (o instrumento avaliativo, a intriga tecida por meio dele), mas também na completude contingente feita pelo leitor (o aluno que refigura a narrativa histórica a ele oferecida).

É preciso sublinhar, porém, que a refiguração não é completamente livre e nem reatualiza o sujeito pleno do Iluminismo, pois o texto, para além dos limites que apresenta, também constrange os processos de leitura. A dialética entre liberdade e coerção é interna ao processo criador e atravessa todo o processo hermenêutico, e é o próprio Ricoeur quem contribui para esse questionamento da plenitude do sujeito:

enquanto o leitor incorpora - consciente ou inconscientemente, pouco importa - os ensinamentos de suas leituras à sua visão de mundo, para aumentar a sua legibilidade prévia, a leitura é para ele algo diferente de um lugar onde ele se detém; ela é um meio que ele atravessa. (RICOEUR, 1997, pp. 303-304, grifos do autor).

Retomando os elementos que compõem a tríade hermenêutica, interessa-me ver mais de perto as relações entre compreensão e explicação, pois ambos participam da leitura, ou seja, da ação narrativa, pois como apresenta o próprio autor, "a compreensão é para a leitura o que o evento do discurso é para a enunciação do discurso, e que a explicação é para a leitura o que a autonomia verbal e textual é para o sentido objetivo do discurso.” (RICOEUR, 2011, p. 102).

O termo interpretação deve ser aplicado a todo o processo que abarca a explicação e a compreensão, pois é ela a dialética entre ambos, de forma que elas são fases de um único processo. O primeiro movimento da interpretação caminha da compreensão para a explicação, quando a compreensão "será uma captação ingênua do sentido do texto enquanto todo" (RICOEUR, 2011, p. 105), que se pode chamar de conjectura. Daí a explicação fará a mediação para um nível mais sofisticado de compreensão, gerando apropriação apoiada em procedimentos explicativos. Entendo, portanto, que a explicação possui um caráter fragmentário, enquanto a compreensão um caráter de totalidade, mas cuja explicação jamais será capaz de representar integralmente, posto que se trata de uma experiência psíquica do autor, e que esta é incomunicável por completo.

Essa proposta de Ricoeur permite validar também a perspectiva de aprendizagem histórica presente em Saddi (2016), entendida como momento do rompimento com os parâmetros até então vigentes de atribuição de sentidos ao mundo, como desestruturação dos referenciais, amplitude do tempo e do espaço e emergência de novos "demônios", o que o autor chama de estado de suspensão, que é 
percebido como crise, como revolução, dado a mudança de paradigmas que provoca, e não como evolução, pois tal estado é impossível de ser comunicado, transferido e, pensando na avaliação, impossível de ser capturado por meio de exercícios, fazendo emergir com força o caráter intuitivo e gerando a necessidade de criação de mecanismos avaliativos no âmbito dessa disciplina que invista no estímulo à produção de conjecturas.

Produzir conjecturas históricas no processo de refiguração narrativa no espaço escolar gera a necessidade e o desafio da validação, que é, em última instância, feita pela avaliação e, como aqui vem sendo defendido, tendo como fonte de parâmetros a Didática da História, pois a narrativa histórica escolar deve garantir a preservação da cientificidade do conhecimento histórico e a inteligibilidade desse conhecimento pelos estudantes da educação básica. Assim, se não há métodos apriorísticos para fazer conjecturas, há de se ter métodos para validar as conjecturas feitas. Ricoeur entende que os procedimentos de validação se aproximam mais da lógica da probabilidade do que de uma lógica da verificação empírica:

Mostrar que uma interpretação é mais provável à luz do que sabemos é algo diferente de mostrar que uma conclusão é verdadeira. Assim, no sentido relevante, a validação não é verificação. É uma disciplina argumentativa comparável aos procedimentos jurídicos usados na interpretação legal, uma lógica da incerteza e da probabilidade qualitativa. (RICOEUR, 2011, pp. 110-111).

A conjectura do sentido do texto se faz necessária porque a intenção do autor é impossível de ser alcançada, assim, deve avaliar-se à luz do próprio texto. A distinção entre intenção mental do autor e o texto desloca para o campo semântico a compreensão, de forma a substituir a intenção pelo sentido. Enfim, compreensão é conjectura e explicação é validação. De acordo com Gabriel (2012):

O corte epistemológico que se opera no plano dos procedimentos está diretamente relacionado com a autonomização da explicação histórica e se justifica por três aspectos inerentes à natureza desse saber: a necessidade de conceituação, a procura de objetividade e os limites dessa objetividade. (GABRIEL, 2012, p. 194).

A compreensão fenomenológica é igualmente apontada por Lautier (2011) como traço comum entre a história escolar e a história acadêmica. Essa autora assinala os processos cognitivos para a apropriação de conhecimentos históricos que, em sua visão, não se diferem em relação aos historiadores, professores de história e alunos: seleção de informação, interpretação figurativa, recursos à analogia e à metáfora. Essas operações cognitivas são mobilizadas por meio de uma compreensão narrativa e o seu conhecimento do mundo vivido. Contudo, a aprendizagem escolar da história mobiliza outros registros de pensamento e é interpelada por constrangimentos da situação didática que não são vistos aqui como deformadores dessa aprendizagem, mas como condição de possibilidade para que elas possam ser validadas, condição indispensável para manter a escola no domínio do verdadeiro, como discutido anteriormente.

Por se referir ao vivido, a inteligibilidade histórica não é apenas lógica (MONTEIRO; PENNA, 2011), e é a estrutura narrativa que condensa as demais operações cognitivas que configuram essa inteligibilidade. Lautier (2011) argumenta que a interpretação figurativa se refere às imagens-chave que contribuem para a construção de representações significativas. As metáforas, em sua visão, cumprem um importante papel, pois "tornam-se o núcleo imagético que estrutura representações socialmente compartilhadas" (LAUTIER, 2011, p. 45, grifos da autora). Já as analogias assumem destacada função na dimensão temporal do conhecimento histórico, podendo ser passado-presente ou passado-passado. Monteiro e Penna (2011) referendam essa perspectiva e sublinham que o uso da comparação e o risco de anacronismo são inerentes ao ensino escolar da História, e é na avaliação que se torna possível observar os limites aceitos para a comparação e o uso controlado de analogias.

Esses elementos destacados por Lautier (2011) foram identificados por meio de pesquisa sobre a circulação dos saberes históricos em sala de aula. A autora traça um quadro interessante sobre a apropriação, por parte dos alunos da educação básica, do conhecimento histórico que é ensinado: 
Em todos os casos observados, ancoragem e objetivação são acionados; acompanhados de todos os processos de seleção das informações (ocultação, recusa, transformação), e completados pelos processos de figuração, o recurso à analogia e à metáfora. Entretanto, as expectativas da situação escolar não podem satisfazer-se destas únicas modalidades de apropriação. A responsabilidade da aprendizagem escolar da história envolve outras modalidades, outros registros de pensamento. (LAUTIER, 2011, p. 47, grifos meus).

O grifo assinalado no excerto trazido da autora francesa permite reafirmar a necessidade de diversificação de instrumentos avaliativos, pois eles se constituem como espaço privilegiado de registro de pensamento. É também nesse sentido que a identidade narrativa apresenta potencial para pensar a avaliação das aprendizagens históricas, pois para além da tradição paradigmática que contextualiza e constrange as refigurações permitidas nos típicos instrumentos avaliativos utilizados nas salas de aula de História, ela admite o "tornar-se presença" e a produção de "experiências" ao fazer a ponte entre o tempo cosmológico coletivo e o tempo fenomenológico individual, constituindo-se, pois, como tempo narrado (RICOEUR, 1997).

Terceiro tempo (tempo narrado) é o entrecruzamento entre a história e a narrativa, que gera a identidade narrativa, sendo o termo identidade concebido com o sentido de uma categoria da prática. A identidade possui um nome próprio, e apenas a narrativa é capaz de oferecer subsídios para pensar a permanência desse nome próprio ao longo de toda a vida. "A história narrada diz o quem da ação. A identidade do quem é apenas, portanto, uma identidade narrativa." (RICOEUR, 1997, p. 424, grifos do autor).

O conceito de identidade narrativa, portanto, não compreende uma noção de identidade como um mesmo (idem), correspondendo a algo que não muda, que é o mesmo do nascimento até a morte, mas apresenta a identidade como um si mesmo (ipse), que compreende mudanças na coesão do eu singular. "A ipseidade é, assim, a de um si instruído pelas obras da cultura que ele aplicou a si mesmo." (RICOEUR, 1997, p. 425). O autor esclarece:

a diferença entre idem e ipse não é senão a diferença entre uma identidade substancial ou formal e a identidade narrativa. A ipseidade pode escapar ao dilema do Mesmo e do Outro, na medida em que sua identidade se baseia numa estrutura temporal conforme ao modelo de identidade dinâmica oriunda da composição poética de um texto narrativo. O si mesmo pode, assim, ser dito refigurado pela aplicação reflexiva das configurações narrativas. Ao contrário da identidade abstrata do Mesmo, a identidade narrativa, constitutiva da ipseidade, pode incluir a mudança, a mutabilidade, na coesão de uma vida. (RICOEUR, 1997, p. 425, grifos do autor).

A relação que os alunos estabelecem com o conhecimento histórico escolar faz parte da constituição da ipseidade, que representa um movimento que tanto pode ser individual, como pode ser coletivo. É no ato de refiguração, que a identidade narrativa se manifesta. É ali que as narrativas oferecidas pelo professor são ressignificadas à luz das experiências e expectativas. É ali que se desenvolve o que Cerri (2010) nomeia como competência narrativa, que sintetiza as dimensões do tempo, do valor e da experiência. A competência narrativa "resulta de um aprendizado, e se reconstrói continuamente, em função das novas experiências e mudanças na realidade e do diálogo com novos argumentos" (CERRI, 2010, p. 274).

A temporalidade que é inerente ao conhecimento histórico, o valor que corresponde à dimensão axiológica que também é inerente ao saber histórico escolar, e a experiência, que diz respeito, em uma perspectiva micro, à significação que o indivíduo impõe às narrativas históricas que lhe são ofertadas, interpelam a ipseidade do sujeito e configuram sua identidade narrativa, produzindo efeitos sobre as refigurações do conhecimento histórico feitas pelo aluno. A ipseidade de Ricoeur pode ser entendida como processos de subjetivação e de identificação que, quando expressa em algum suporte, contempla também os processos de objetivação que, no caso dos sistemas educacionais, constituem o objeto a ser avaliado.

Se a avaliação contempla a refiguração feita pelos alunos das narrativas explicadas pelos professores em sala de aula - processo este marcado pelos limites do próprio texto, pelos constrangimentos do contexto de escolarização, pela mobilização de subjetividades, a identidade narrativa objetivada nos instrumentos avaliativos disponibilizados também será objeto de leitura por parte daqueles 
que na ordem social escolar estão legitimados a estabelecer o corte antagônico das narrativas que podem, ou não, ser consideradas válidas - os professores - implicando assim uma nova inserção na espiral que caracteriza o círculo hermenêutico. Ou seja, a leitura do aluno objetivada em um instrumento avaliativo leva à necessidade de leitura do professor, que não mais estará, no contexto do círculo hermenêutico, na mesma posição de quando produziu o texto oferecido ao aluno para leitura, sustentando a tese ricoeuriana de um círculo espiralado. Se é a leitura que finaliza o texto, o que se avalia não é necessariamente o que foi escrito no texto, mas o que foi compreendido pelo leitor, havendo aí uma discrepância que torna a avaliação um ato impossivel.

Mais do que a dificuldade de avaliar aspectos relativos à formação cidadã/cívica, como apontado por Lautier (2011), a impossibilidade da avaliação no ensino de História parece estar no hiato inescapável entre o escrito e o lido, quando se trata de permitir refigurações das narrativas históricas, sendo então a memorização de conteúdos a saída prática comumente encontrada para tornar possível avaliar no âmbito dessa disciplina escolar.

A possibilidade de fazer trabalhar essa aporia é investindo no sentido de análise de probabilidade e de argumentação para o significante avaliação. Isso significa admitir que identidades narrativas fixadas em instrumentos avaliativos devem abarcar relações pessoais com o conhecimento histórico escolar (conteúdos científicos incluídos) e compromisso com valores democráticos, de forma que o eu que está sendo narrado, que não existe a priori, mas emerge e se torna presença nessa narrativa, não seja uma autoexpressão qualquer, mas um en que se relaciona nas/com as temporalidades, justificando a pertinência do ensino de História como instituição de formação.

A identidade narrativa, portanto, não implica abandonar os conhecimentos, mas se relacionar com eles. Ela permite romper com o caráter teleológico do conhecimento histórico escolar ao, por exemplo, imaginar outros passados e presentes possíveis, e isso só é passível de ser feito se houver aprendizado com conteúdos. Ela permite romper com a tautologia que caracteriza os exercícios nessa disciplina escolar (ROCHA, 2009), isto é, admite a possibilidade de romper com a pura repetição para permitir a emergência do sujeito por meio da "adequação entre a singularidade da solução que constitui por si mesma a obra e a singularidade da conjuntura de crise" (RICOEUR, 1997, p. 280), se se considera uma obra como a solução de um problema forjado. "Numa palavra, a identidade narrativa é a solução poética do círculo hermenêutico." (RICOEUR, 1997, p. 427). O lugar social de validação dessas identidades narrativas produzidas em situação escolar é a Didática da História, que hibridiza o código e a comunidade disciplinares da História, e a epistemologia da História e a Epistemologia Social Escolar, formando uma cultura histórica escolar que serve de base para a definição de exigências cognitivas específicas do pensar historicamente no contexto escolar.

Longe de querer estabelecer um modelo a ser seguido em termos de avaliação das aprendizagens históricas - o que consistiria em uma dissonância em relação ao que aqui está sendo proposto - mas como forma de trazer elementos empíricos para a discussão, deixando-os absolutamente aberto às necessárias críticas, apresento um instrumento produzido e aplicado por mim do lugar de professor de História da educação básica, que ocupei por 10 anos, à alunos do Ensino Médio. Ainda que ele não satisfaça todos os elementos aqui mobilizados na construção do que estou chamando de avaliação democrática das aprendizagens históricas, até porque foi produzido e aplicado previamente ao fechamento dos estudos que culminam nesse texto, entendo que ele carrega rastros desses elementos, com potenciais para serem explorados e desenvolvidos em cada contexto de ensino-aprendizagem-avaliação no âmbito da História escolar.

Chamei esse objeto de Memorial e apresentei seu conceito como sendo "Construção de um registro (escrito ou audiovisual) autoral e individual sobre a trajetória percorrida e as experiências obtidas ao longo do bimestre na relação com a disciplina História. As aprendizagens devem ser demonstradas da forma que o aluno achar melhor: texto, vídeo, desenho, charge, meme, quadrinho, música, etc.”. Como objetivos indiquei: i) Identificar momentos de aprendizagem dos alunos; ii) Exercitar a abordagem crítica autoral; iii) Aproximar os conteúdos disciplinares do contexto geral do aluno.

Os elementos metodológicos para orientar a elaboração do Memorial, independente da linguagem escolhida, deveriam contemplar: i) manifestação na primeira pessoa do singular; ii) 
apresentação do aprendizado obtido; iii) relação com temas contemporâneos gerais da sociedade e/ou específicos da vida dos alunos; iv) elaboração de uma análise crítica e propositiva; v) referências.

Explicitar os conceitos, os objetivos e os contornos metodológicos articula as dimensões política e técnica que interpelam qualquer processo avaliativo. Assim, torna-se necessário ainda apresentar os critérios de correção/validação das narrativas que seriam produzidas pelos discentes. Os critérios definidos foram $^{2}$ : i) caráter autoral do memorial $(1,0)$; ii) coerência e coesão $(0,5)$; iii) cumprimento das etapas metodológicas $(2,5)$; iv) articulação presente-passado-futuro (1,5); v) uso pertinente das analogias e metáforas $(1,5)$; vi) compromisso com valores democráticos e com os Direitos Humanos $(1,5)$; vii) Argumentação com base em conhecimentos históricos (1,5).

Não cabem nas balizas desse texto explorar cada um dos elementos apresentados nesse instrumento avaliativo, tampouco analisar os produtos advindos dessa proposta de avaliação das aprendizagens históricas, o que também não quer dizer que o leitor não possa fazê-lo à medida de seus interesses sobre a temática e como forma de contribuição ao debate. Esses importantes movimentos virão, de minha parte, em trabalhos futuros. Para os objetivos desse artigo, a apresentação dessa proposta serve como provocação inicial para fomentar discussões acerca das possibilidades de uma avaliação no âmbito do ensino de História que esteja inserida no que aqui foi chamado de cultura histórica escolar, sem que essa inserção signifique reduzir a avaliação de História na educação básica à verificação simples de acúmulo de conteúdos ou a reprodução das palavras de outrem.

\section{CONSIDERAÇÕES FINAIS}

Pensar historicamente na perspectiva da cultura histórica escolar é, ao mesmo tempo, incorporar os constrangimentos das situações didáticas como condição desse pensamento; é articular mudanças, permanências e cronologias em uma totalidade precária que articula processos de subjetivação, identificação e objetivação; é considerar a bagagem trazida pelo aluno para a viagem no tempo que uma aula de história deve proporcionar (ROCHA, 2009); é descentrar-se em busca da empatia necessária à compreensão dos movimentos de homens e mulheres que viveram outros presentes que não o nosso; é incorporar as experiências produzidas no tempo vivido narrado de forma a produzir novas experiências; é assumir a indução e a intuição como seus componentes (SIMAN, 2015); é incorporar a sensibilidade e a imaginação em seu processo constitutivo (PEREIRA; CHEPP, 2018); é, pois, como sugere Plá (2013b), articular as implicações da socialização e subjetivação dos processos de escolarização.

Identificar, explicar e relacionar são operações cognitivas não restritas à história escolar, havendo, portanto, a necessidade de complementação para que elas se tornem operações cognitivas históricas, e o elemento que confere essa identidade é a dimensão temporal. Transitar no tempo interpela as afetividades sem um sentido previamente definido. Mergulhar no passado, atribuir sentidos outros para o presente em função desse mergulho, assim como sonhar ou temer futuros possíveis não possuem um caráter positivo ou negativo antes do mergulho ser feito e nem atinge a todos da mesma forma, pois o mergulho não é apenas coletivo, mas, sobretudo, individual, mobilizando bagagens singulares, mas que de forma aparentemente paradoxal, comportam experiências coletivas, reativando assim a tensão universal/particular inerente aos processos de significação do mundo.

Pereira e Chepp (2018) defendem a escrita de narrativas históricas por discentes com base na criação e imaginação, pois ler e escrever conformam a subjetividade e determinam um sentido, assumindo assim, compromisso com a autoria, com o "tornar-se presença", com a construção de "experiências", escapando à cópia e à repetição dos argumentos do texto que lhe é oferecido em sala, seja do livro didático, do professor, ou de qualquer outro polo enunciador de narrativas históricas, fugindo da prisão da palavra dada, pois para esses autores, "Escrever e ler estando em abertura e exposto às forças que vêm de Fora é algo que implica fazer dessas práticas não simplesmente exercícios de representação ou de comunicação, mas torná-las, por excelência, atividades do pensamento." (PEREIRA; CHEPP, 2018, p. 2).

\footnotetext{
${ }^{2}$ Os valores apresentados entre parênteses correspondem a pontuação máxima que poderia ser obtida em cada critério para a composição da nota.
} 
É nesse movimento imaginativo que o aluno é capaz de atribuir sentido ao tempo, rompendo com uma perspectiva ainda hegemônica que situa a escola, a aula de História, e principalmente a avaliação no âmbito dessa disciplina, como meros espaços de reprodução das cronologias e de uma História fria e disciplinada. Perceber o tempo como labiríntico ou rizomático, como argumentam Pereira e Chepp (2018), possibilita uma leitura de um determinado contexto como efeito de diversas alternativas que se apresentaram no jogo de forças, rompendo com o caráter tautológico e teleológico que caracterizam as narrativas discentes (re)produzidas nos instrumentos avaliativos dessa disciplina.

Esse entendimento mantém a relação com o conhecimento histórico, o faz dialogar com o vivido, preserva as perspectivas temporal, política e axiológica que configuram esse conhecimento em sua dimensão escolar, deslocando para a Didática da História a responsabilidade de validação. Afinal, como informa Umbelino (2018), a formação no âmbito das humanidades envolve pensar criticamente, refletir de modo alternativo, imaginar criativamente, recordar livremente, antecipar na diferença, mudar e acolher informadamente o inesperado, e a avaliação democrática das aprendizagens deve estar a favor desse processo.

\section{REFERÊNCIAS}

ÁLVAREZ MÉNDEZ, Juan Manuel. Evaluar para conocer, examinar para excluir. Madrid: Editora Morata, 2001.

ARENDT, Hannah. A condição humana. Tradução de Roberto Raposo, posfácio de Celso Lafer. $10^{\mathrm{a}}$ ed.; Rio de Janeiro: Forense Universitária, 2007.

BIESTA, Gert. Para além da aprendizagem: educação democrática para um futuro humano. $1^{\text {a }}$ ed.; 1. Reimp. Belo Horizonte: Autêntica Editora, 2017.

BONDÍA, Jorge Larrosa. Notas sobre a experiência e o saber de experiência. Revista Brasileira de Educação, n. 19, p. 20-28, jan./abr., 2002.

CERRI, Luis Fernando. Didática da História: uma leitura teórica sobre a História na prática. Revista de História Regional 15(2): 264-278, Inverno, 2010.

CHAIB, Mohamed. Representações sociais, subjetividade e aprendizagem. Cadernos de Pesquisa. V. 45, n. 156, p. 358-372, abr./jun, 2015.

CORRÊA, Nancy Nazareth Gatzke; PASSOS, Marinez Meneghello; ARRUDA, Sergio de Mello. Metacognição e as relações com o saber. Ciênc. Educ., Bauru, v. 24, n. 2, p. 517-534, 2018.

GABRIEL, Carmen Teresa. Cultura histórica nas tramas da didatização da cultura escolar (ou Para uma outra definição de didática da história). In: Helenice Rocha, Marcelo Magalhães, Rebeca Gontijo (Orgs.). O ensino de história em questão: cultura histórica, usos do passado. Rio de Janeiro: FGV Editora, 2015. p. 77-96.

GABRIEL, Carmen Teresa. Discurso, demandas e fronteira: articulações teórico-metodológicas na análise de textos curriculares. Revista da FAEEBA - Educação e Contemporaneidade, Salvador, v. 22, n. 40, p. 55-67, jul./dez. 2013.

GABRIEL, Carmen Teresa. O processo de produção dos saberes escolares no âmbito da disciplina de história: tensões e perspectivas. Educação Básica Revista, vol.3, n.2, 2017. 
GABRIEL, Carmen Teresa. Relação com o saber: uma proposta de releitura pós-fundacional in LOPES, A.C.; OLIVEIRA, A.L.M. de; OLIVEIRA, G.G.S. de (orgs). In: A teoria do discurso na pesquisa em educação, Recife, Editora UFPE, 2018. p. 217-250.

GABRIEL, Carmen Teresa. Teoria da História, Didática da História e narrativa: diálogos com Paul Ricoeur. Revista Brasileira de História. São Paulo, v. 32, nº 64, p. 187-210, 2012.

GABRIEL, Carmen Teresa; MORAES, Luciene Maciel Stumbo. Conhecimento escolar e conteúdo: possibilidades de articulação nas tramas da didatização. In: GABRIEL, C. T.; MORAES, L. M. S.; (Orgs.). Currículo e conhecimento: diferentes perspectivas teóricas e abordagens metodológicas. $1^{\mathrm{a}}$ ed. Petrópolis, RJ: De Petrus: Faperj, 2014. p. 23-42.

GABRIEL, Carmen Teresa; MONTEIRO, Ana Maria. Currículo de História e Narrativa: desafios epistemológicos e apostas políticas. In: Ana Maria Monteiro [et al.]. Pesquisa em ensino de história: entre desafios epistemológicos e apostas políticas. 1. ed. - Rio de Janeiro: Mauad X: Faperj, 2014. p. 2340.

JARVIS, Peter. Aprendizagem humana: implícita e explícita. Educação \& Realidade, Porto Alegre, v. 40, n. 3, p. 809-825, jul./set. 2015.

LACLAU, Ernesto; MOUFFE, Chantal. Hegemonia e estratégia socialista: por uma política democrática radical. São Paulo: Intermeios, 2015.

LAUTIER, Nicole. Os Saberes Históricos em Situação Escolar: circulação, transformação e adaptação.

Educ. Real., Porto Alegre, v. 36, n.1, p. 39-58, jan./abr., 2011.

LAVILLE, Christian. Guerra de narrativas: debates e ilusões em torno do ensino de História. Revista Brasileira de História. São Paulo, v. 19, nº 38, p. 125-138. 1999.

LIBÂNEO, José Carlos. A didática e a aprendizagem do pensar e do aprender: a Teoria Histórico-cultural da Atividade e a contribuição de Vasili Davydov. Revista Brasileira de Educação, n. 27, p. 5-24, set./dez., 2004.

LINGIS, Alphonso. The Community of those who have nothing in common. Bloomington and Indianapolis: Indiana University Press, 1994.

MONTEIRO, Ana Maria. Professores de história: entre saberes e práticas. Rio de Janeiro: Mauad X, 2007.

MONTEIRO, Ana Maria; PENNA, Fernando de Araujo. Ensino de História: saberes em lugar de fronteira. Educ. Real., Porto Alegre, v. 36, n.1, p. 191-211, jan./abr., 2011.

PENNA, Fernando. A relevância da didática para uma epistemologia da História. In: Ana Maria Monteiro [et al.]. Pesquisa em ensino de história: entre desafios epistemológicos e apostas políticas. 1. ed. - Rio de Janeiro: Mauad X: Faperj, 2014. p. 41-52.

PEREIRA, Nilton Mullet; CHEPP, Bruno. Ler e escrever nas aulas de história: da prisão da palavra ao labirinto do exterior. Fênix - Revista de História e Estudos Culturais. Janeiro - Junho de 2018, Vol.15, p. 1-18, Ano XV, no 1.

PLÁ, Sebastián. La ilusión científica de la didáctica de la historia: provocaciones teóricas sobre el conocimiento histórico escolar. In: Blázquez, Juan Carlos, Latapí Escalante, Paulina y Torres Salazar, 
Hugo, Memoria del Cuarto Encuentro Nacional de Docencia, Difusión y Enseñanza de la Historia. Segundo Encuentro Internacional de Enseñanza de la Historia. Tercer Coloquio entre tradición y modernidad, México, Reddieh, 2013a, p. 474-483.

PLÁ, Sebastián. Pensar historicamente: reflexiones para la investigación em Enseñanza de la Historia. In: Xavier Rodríguez Ledesma, Ariana Toriz Martinez, María del Carmen Acevedo Arcos (Orgs.). Tercer Encuentro Nacional de Docencia, Difusión y Enseñanza de la Historia y Primer Encuentro Internacional de la Enseñanza de la Historia. México: UPN, 2013b, p. 240-251.

RICOEUR, Paul. Tempo e narrativa - Tomo III. Campinas, SP: Papirus, 1997.

RICOEUR, Paul. Teoria da Interpretação: o discurso e o excesso de significação. Lisboa: Edições 70, 2011.

ROCHA, Helenice Aparecida Bastos. Aula de história: que bagagem levar? In: Helenice Aparecida Bastos Rocha, Marcelo de Souza Magalhães e Rebeca Gontojo (Orgs.). A escrita da história escolar: memória e historiografia. Rio de Janeiro: Editora FGV, 2009. p. 81-104.

SADDI, Rafael. Didática da história como sub-disciplina da Ciência Histórica. História \& Ensino, Londrina, v. 16, n. 1, p. 61-80, 2010.

SADDI, Rafael. O Estado de Suspensão na aprendizagem histórica: a força estética do conhecimento histórico na instauração de um momento sublime de consciência histórica. Revista História Hoje, v. 5, $\mathrm{n}^{\circ}$ 9, p. 113-130, 2016.

SIMAN, Lana Mara de Castro. Aprender a pensar historicamente: entre cognição e sensibilidades. In: Helenice Rocha, Marcelo Magalhães, Rebeca Gontijo (Orgs.). O ensino de história em questão: cultura histórica, usos do passado. Rio de Janeiro: FGV Editora, 2015. p. 201-222.

UMBELINO, Luís António. O fim das humanidades: ensino e aprendizagem em época de crise. Cadernos de Pesquisa, v.48, n.167, p.192-202 jan./mar. 2018.

VELASCO, Diego Bruno. "Realidade do aluno", “Cidadão Crítico”, “Conhecimento escolar": Que articulações possíveis no Currículo de História? 2013. 180f. Dissertação (Mestrado em Educação). Faculdade de Educação, Universidade Federal do Rio de Janeiro, Rio de Janeiro, 2013.

Submetido: $08 / 08 / 2019$

Aprovado: $21 / 03 / 2020$ 